\title{
India's Vast Potential for Clinical Outcomes Research—a Global Leader in Waiting!
}

\author{
Chandrakanth Are ${ }^{1}$
}

Received: 28 May 2016 / Accepted: 28 June 2016 / Published online: 4 July 2016

(C) Indian Association of Surgical Oncology 2016

India is a vast country with a population of 1.25 billion (2015). With a population growth rate of $1.22 \%$, the population of India is due to surpass that of China in the near future [1]. This rising population will significantly increase the health care needs of the expanding nation. In addition, with a gross domestic product (purchasing power parity adjusted for 2015) of $\$ 8.027$ trillion and a gross domestic product growth rate of $7.3 \%$ (2015), India is categorized as an emerging economy. Improving economic standards injects "transitions" into various aspects of the country's fabric. Similar to the phenomenon of "economic transition" (initiated in the 1990s), India is currently meandering its way through "transitions" involving health care delivery, education, etc. The improving living standards, combined with an increasingly medically literate population, demands the delivery of high-quality, value-appropriate, timely, compassionate, and evidence-based care.

While several factors influence the delivery of high-quality health care, one of the most important steps starts with assessment of the current status. A rigorous assessment of the current health care delivery based on stringent quality metrics serves as the stimulant to address areas for improvement. Several systems consisting of variable metrics have been implanted into practice in the USA such as the Surgical Care Improvement Project (SCIP) [2] and Patient Safety Indicators [3]. In addition to these government-mandated metrics, the surgical community in the USA has been pioneering the way in assessing its own outcomes and setting the standards of care far ahead of most other disciplines. The ACS National Surgical Quality Improvement Program (ACS

Chandrakanth Are care@unmc.edu

1 University of Nebraska Medical Center, Omaha, NE 68198, USA
$\mathrm{NSQIP}^{\circledR}$ ) is a prime example, which is a clinical database that is maintained and monitored by surgeons [4]. The ACS NSQIP ${ }^{\circledR}$ provides the platform that has been used extensively to conduct research into clinical outcomes which can contribute to improved patient care. It is this real-time research in clinical outcomes that can be the driver to improve patient care in real time.

Research can extend across several realms from basic science and translational to clinical research. The ability to conduct research in any of these avenues depends on the presence of particular academic capital and financial resources specific to each avenue. Full-scale basic and translational science research conducted by clinical surgeons may be in its infancy in India due to a multitude of barriers and reasons. But the barriers to conducting clinical outcome research should theoretically be fewer in India. A very simplified schema of clinical outcomes research pipeline is presented in Fig. 1. A review of this schema can highlight the strengths but more importantly focus on the weak links that are preventing India from becoming a powerhouse for clinical outcome research.

To begin with, a good clinical outcome study needs the presence of a large pool of patients. The larger the "n," the more weighty are the conclusions. With its rising population and increase in the number of diseases, India has the potential to contribute to large clinical outcome studies. A review of the abstracts submitted to the annual meeting of the Indian Association of Surgical Oncology (IASO) reveals the strength in numbers. A study that highlighted a novel and less-invasive technique for port placement was able to document the outcomes for 1200 patients in a short period of 5 years. A study to determine the feasibility of laparoscopic radical hysterectomy for early-stage cervical cancer over a period of less than 5 years included 224 patients. Similarly, a study on the emerging field of cytoreductive surgery in India was able to accrue 87 


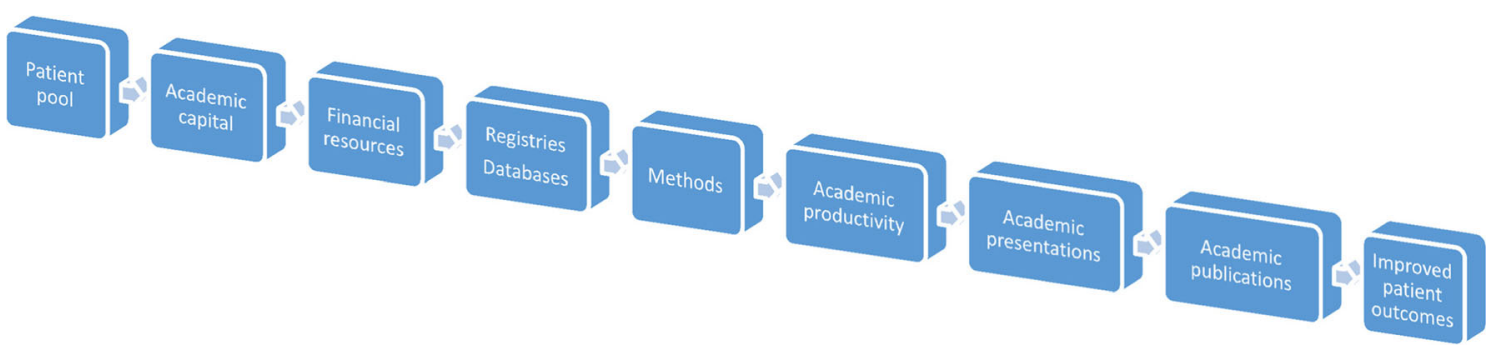

Fig. 1 Clinical outcome research schema

patients in 18 months. These large volumes of patients seem to extend across malignancies involving many organ systems. The potential to include such large numbers of patients in clinical outcomes studies (albeit retrospective) over short periods of time has the ability to change practice habits in real time to deliver better patient care.

In addition to the presence of large patient pools, the ability to conduct clinical outcome research depends on the presence of academic capital and financial resources. India can now boast of possessing one of the largest pools of young academic capital in the world. By 2020, India will have 900 million working age Indians with an average age of 29 [5]. It's significant strength includes the presence of an impressively large pool of academic capital in every field including medicine and surgery. The number of talented surgical oncologists is impressive and is rapidly rising with an increase in the number of Mch and DNB programs.

The abundance of academic capital is in stark contrast to the lack of or inadequate financial resources. This lack of financial support to nurture the academic activities of trainees and surgeons in practice is of particular concern. This combined with the large and growing clinical loads leaves minimal to no time for the inadequately staffed surgical workforce to embark on any meaningful research. The lack of financial resources is also an impediment for setting up cancer registries and databases. Several population- and hospital-based registries are currently in place in India [6]. Despite this, data pertaining to the majority of cancer patients is probably not captured. Another area for improvement is the investments that are needed to support academically oriented trainees and faculty with education in research concepts, methodological input, statistical support, and database maintenance. The lack of this research infrastructure for trainees and faculty to rely on is a major impediment to increasing activity in clinical outcome research.

There is no country other than India, a bastion of information technology, that is better suited to address the deficiencies associated with its own research infrastructure. With its behemothic arsenal of information technology, India should develop novel, no frills, low-cost, technologically spartan but adequate database platforms to acquire and analyze data. Such platforms should be specifically developed for the nascent research environment prevailing in India. It should also develop remote assistance channels that can be utilized to provide assistance with data acquisition and analysis for participants practicing in remote and austere environments. These innovative research platforms ("desktop to outcome") can serve as prototypes for $80 \%$ of the world where the research environment is more akin to India than to the OECD countries from where most of the current research originates from. One can only imagine what this large pool of academic capital in India can accomplish with the right tools and supportive environment.

In spite of these drawbacks, we are noticing a rising interest to augment the level of academic productivity in the field of surgical oncology. A review of the abstracts submitted to the annual meeting of the IASO, 2015, demonstrates that rising interest. The abstracts cover an impressive variety of malignancies ranging from gastrointestinal, head and neck, gynecological, endocrine, hepatobiliary, orthopedic, urological, and thoracic malignancies. They include a mosaic of abstracts that included small to large cohorts of patients, research into new technology as well as some presentations of rare cases. In previous meetings, some well-conducted clinical randomized controlled trials were presented.

In my interactions with the attendees at the annual meetings of the IASO over the past several years, I have witnessed this strongly palpable urge by the leadership to stimulate research and by the trainees and faculty to get more involved in academic activities. This interest is uniformly spread across all levels of training and as well as for faculty in practice. The IASO provides a good platform for the trainees and young faculty in practice to present their research data, which could ultimately lead to peer-reviewed publications. The Indian Journal of Surgical Oncology, published by the IASO, and other journals provide that platform to publish their data which may help in dissemination of best practices which ultimately can contribute to improved patient care. The IASO and its leadership needs to be commended for its principled approach to nurture the academic activities and research productivity for the next generation of surgical oncologists. This is evident in the support provided for six young surgical oncologists that were able to travel to the annual meeting of the 
Society of Surgical Oncology in Boston in March 2016 to present their research findings.

In summary, India's potential to conduct clinical outcomes research is tremendous. Despite the aforesaid drawbacks, we are witnessing a rise in the level of academic productivity. Strategic investments (academic and financial) combined with the support of reputable national organizations such as IASO and institutions can address these deficiencies over a period of time. These efforts can catalyze the much needed explosive growth and catapult India to serve a vital leadership role on the global stage of clinical outcome research.

\section{References}

1. https://www.cia.gov/library/publications/the-worldfactbook/geos/in.html. Accessed 15 May 2016

2. https://www.jointcommission.org/surgical_care_improvement_ project/. Accessed 15 May 2016

3. http://www.qualityindicators.ahrq.gov/modules/psi_overview.aspx. Accessed 15 May 2016

4. https://www.facs.org/quality-programs/acs-nsqip. Accessed 15 May 2016

5. http://money.cnn.com/2016/04/08/news/economy/india-populationskills-gap-education/. Accessed 15 May 2016

6. http://www.ncrpindia.org/Annual_Reports.aspx. Accessed 15 May 2016 